\title{
Role for Endocytosis in Conjugation in Tetrahymena
}

\author{
MINNA B. ROTHEIM ${ }^{1 *}$ AND BRUCE LOVE ${ }^{2}$ \\ Department of Microbiology, Upstate Medical Center, State University of New York, Syracuse, New York \\ 13210, ${ }^{1}$ and Department of Biochemistry, University of Rochester Medical Center, Rochester, New York
} 14642

\section{Received 11 September 1981/Accepted 15 February 1982}

\begin{abstract}
We examined the effect of inhibitors of receptor-mediated endocytosis on cell pair formation during conjugation in Tetrahymena thermophila. Dansylcadaverine $(20 \mu \mathrm{M})$, methylamine $(20 \mathrm{mM})$, and bacitracin $(2 \mathrm{mg} / \mathrm{ml})$ prevented cell pair formation even when added poststarvation, after mixing of cells of opposite mating types (during the prepairing interaction). Chloroquine (10 and $25 \mu \mathrm{M})$ did not inhibit cell pair formation, leading to the conclusion that inhibition by dansylcadaverine, methylamine, and bacitracin is not due to an alkalinization of the lysosome. These results did not allow us to define the time in the prepairing interaction at which inhibition occurs, nor to identify the cellular components involved, but they did support the hypothesis that an endocytotic event(s) plays a role in the cell contact-mediated recognition which occurs during the prepairing interaction.
\end{abstract}

In Tetrahymena thermophila, conjugation normally occurs only between cells of different mating types. This type of cell recognition, based on mating type, has been described as a self incompatibility system (10) and is based on several codominant alleles known to occur at a single mating type locus (mat). The first two steps in conjugation have been defined as initiation and costimulation (2). The initiation step is elicited by placing the cells in a nonnutrient medium and will occur in the absence of cells of complementary mating types. Initiation may be defined as the time required under starvation conditions to make cells competent to conjugate. This is followed by a prepairing interaction (8), termed costimulation (3), which requires a transient contact between cells of different mating types. Cells are first observed to form pairs about 30 min after mixing of initiated cells of opposite mating types.

The prepairing interaction (cell contact-dependent step) is thought to be a trigger which acts to initiate pairing and the complex developmental sequence resulting in genetic exchange. We hypothesized that transient cell contact allows the exchange of cell surface ligands by receptor-mediated endocytosis.

It has been shown (5-7) that several diverse inhibitors of the cytoplasmic enzyme transglutaminase (bacitracin, dansylcadaverine, methylamine) inhibit receptor-mediated endocytosis. In this communication, we report the results of experiments in which we investigated the inhibition of cell pair formation between initiated competent cells by the inhibitors of receptormediated endocytosis. All of the inhibitors stud- ied prevented cell pair formation. It was not necessary for any of these inhibitors to be present during starvation (initiation) to prevent formation of cell pairs. These experiments, however, did not allow us to define the time in the prepairing interaction at which inhibition occurs or to identify cellular components involved in the endocytotic process.

\section{MATERIALS AND METHODS}

Strains and media. All strains were obtained from either P. Bruns (Cornell University, Ithaca, N.Y.) or D. Nanney (University of Illinois, Urbana). For all conjugation experiments, strain B-1868 mating types III and VII were used (described in [11]). All strains were maintained axenically with biweekly transfer in PYS medium (1\% proteose peptone, $0.1 \%$ yeast extract, $0.003 \%$ sequestrene). Cell assays (singles and pairs) were done by mixing equal portions of cells and DaFano fixative (4); cells were counted in a Sedgewick-Rafter chamber. At least 600 cells were counted when determining cell titers, and at least $\mathbf{4 0 0}$ cells were counted when determining the percentage of cells in pairs. The latter was calculated as $\{[2$ (number of cell pairs)]/[number of single cells +2 (number of cell pairs)]\} $\times 100$.

Conjugation experiments. The procedures followed were those of Orias and Bruns (11) or Wolfe and Grimes (15). For conjugation experiments, the strains to be used were serially transferred twice; for the second transfer, cells of opposite mating types were grown for 36 to $48 \mathrm{~h}$ at $28^{\circ} \mathrm{C}$ with shaking to a final concentration of $6 \times 10^{5}$ to $8 \times 10^{5} / \mathrm{ml}$. Each culture was then washed three times in either $10 \mathrm{mM}$ Tris (pH 7.4) or Dryls buffer (9). Washed cells of each mating type were suspended separately in buffer to a final concentration of $3 \times 10^{5}$ to $5 \times 10^{5} / \mathrm{ml}$. These cells were starved without shaking at $28^{\circ} \mathrm{C}$ for 12 to $14 \mathrm{~h}$. Equal numbers of starved cells of the different mating 
types were mixed (final concentration, ca. $5 \times 10^{5} / \mathrm{ml}$ ) and incubated at $28^{\circ} \mathrm{C}$ without shaking. At designated times after mixing, samples were removed, and the appropriate inhibitor was added. Time zero $\left(t_{0}\right)$ was the time at which the two initiated (starved) cultures were mixed.

Starvation-conditioned medium (SCM) was the supernatant (buffer) obtained from the overnight starvation cultures after removing cells by centrifugation. This SCM (1) was used to suspend cells after washing in reversibility experiments (described below).

Inhibitors. The inhibitors used in our experiments were bacitracin $(2.0 \mathrm{mg} / \mathrm{ml})$, dansylcadaverine $(20$ $\mu \mathrm{M})$, methylamine $(20 \mathrm{mM})$, and chloroquine $(10,25$, 50 , or $100 \mu \mathrm{M})$. All reagents were obtained from Sigma Chemical Co., St. Louis, Mo. Because of low solubility, dansylcadaverine was dissolved in $\boldsymbol{N}, \boldsymbol{N}$-dimethylformamide (Fisher Scientific Co., Pittsburgh, Pa.). In experiments with this compound, an equal amount of dimethylformamide (without inhibitor) was always added to control mixtures.

Reversibility. Conjugation experiments were done as described above. Equal numbers of starved cells of different mating types were mixed and divided into three subcultures. One subculture was the control; inhibitor was added to the other two subcultures at $t_{0}$. Approximately $45 \mathrm{~min}$ later (or when the control culture showed about $10 \%$ of cells in pairs), one of the to cultures containing inhibitor was centrifuged; the cells were then washed three times with fresh Tris and suspended in SCM (described above). This washed subculture, the unwashed subculture still containing inhibitor, and the control mixture were all sampled at various time intervals.

\section{RESULTS}

Inhibition of pair formation. Inhibition of cell pair formation by three of the compounds (bacitracin, dansylcadaverine, and methylamine) is shown in Fig. 1a-c. With all of these reagents we observed that pair formation was inhibited if the compound was added within $1 \mathrm{~h}$ after mixing of competent cells. Cells exposed to bacitracin continued to form pairs at the same rate as that of the control for about $\mathbf{3 0} \mathrm{min}$, after which time no new pairs were formed. This delay in action could simply reflect low cell permeability to this inhibitor. When any of the inhibitors were added $1 \mathrm{~h}$ after mixing $\left(\mathrm{t}_{0}+60 \mathrm{~min}\right)$, the results observed were variable and depended on both the agent used and its concentration. For bacitracin, addition at any time after mixing allowed pair formation to continue for about $30 \mathrm{~min}$, after which time no new cell pairs were formed. However, when dansylcadaverine (Fig. 1b) or methylamine (Fig. 1c) were added $1 \mathrm{~h}$ or more after mixing of cells, there appeared to be a dissociation of the pairs already formed. These results were consistent and repeatable (all experiments reported were repeated at least three times), and the dissociation was not due to mechanical separation of pairs by pipetting. These data thus revealed a physiological heterogeneity between early and late pairs.

Growth in the presence of inhibitors. The inhibition of pair formation was not due to the effect of these inhibitors on growth. Figures $2 a-c$ show the growth of strain B-1868 III in the presence of the same concentrations of inhibitor that were used for the experiments shown in Fig. 1a-c. In each case, growth occurred at the same rate in the presence or absence of inhibitor for a period of $24 \mathrm{~h}$. (All conjugation experiments were carried out for a maximum of 4 to $5 \mathrm{~h}$.)

Reversal of inhibition. The data shown in Fig.
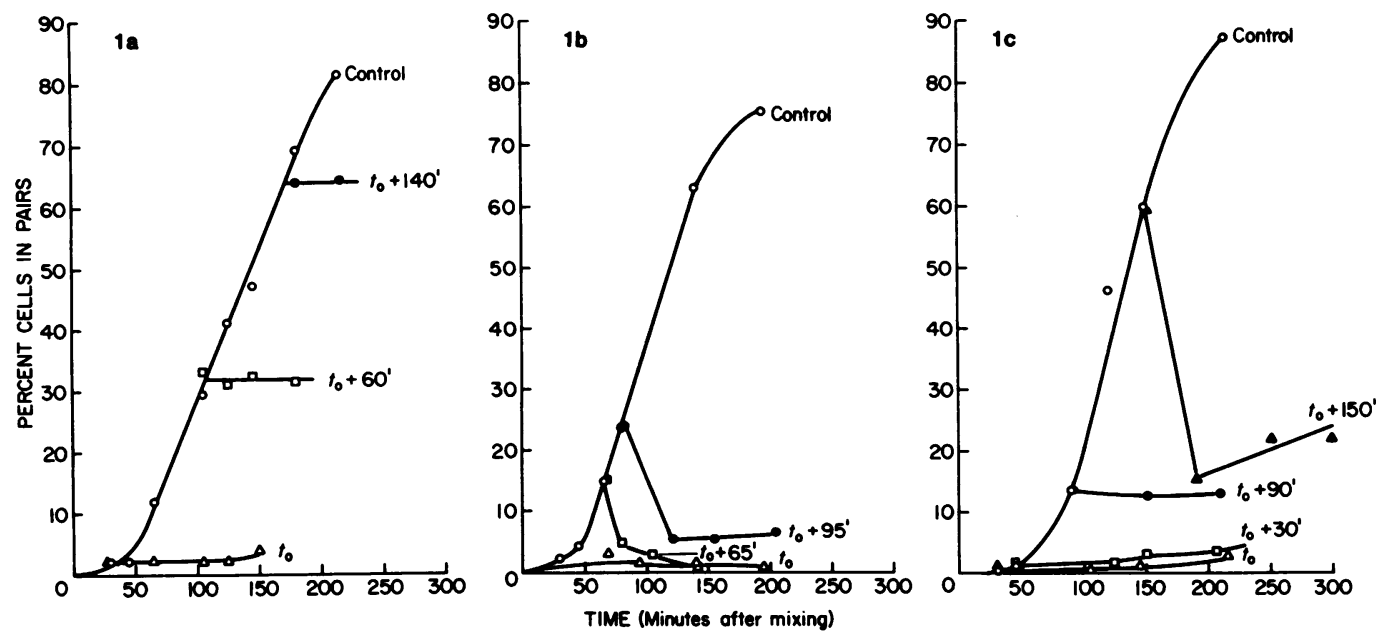

FIG. 1. Inhibition of cell pair formation. (a) Inhibition by bacitracin $(2.0 \mathrm{mg} / \mathrm{ml})$. O, Control without bacitracin. Bacitracin was added at $t_{0}(\Delta), t_{0}+60 \mathrm{~min}(\square)$, and $t_{0}+140 \mathrm{~min}(0)$. (b) Inhibition by dansylcadaverine $(20 \mu \mathrm{M})$. $\bigcirc$, Control without dansylcadaverine. Dansylcadaverine was added at $t_{0}(\Delta), t_{0}+65$ $\min (\square)$, and $t_{0}+95 \mathrm{~min}(O)$. (c) Inhibition by methylamine $(20 \mathrm{mM})$. $O$, Control without methylamine. Methylamine was added at $t_{0}(\triangle), t_{0}+30 \min (\square), t_{0}+90 \min (O)$, and $t_{0}+150 \min (\Delta)$. 

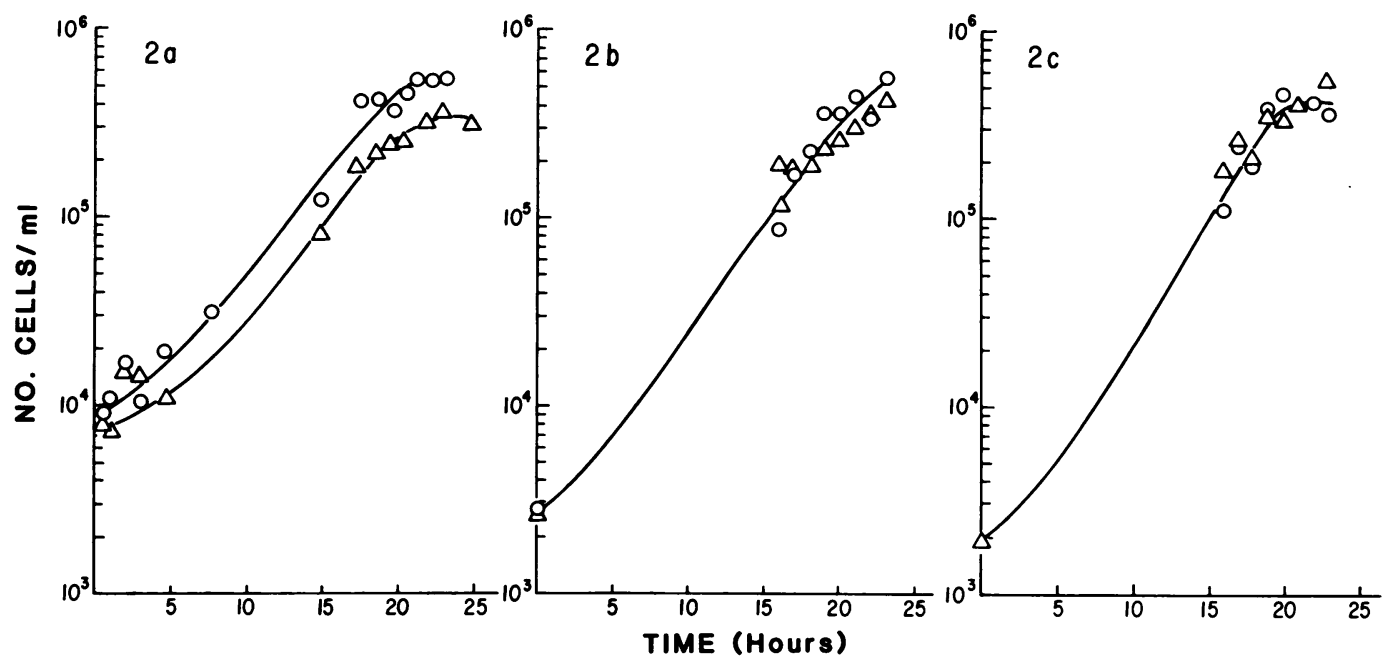

FIG. 2. Growth of strain B-1868 III in presence of inhibitors. (a) Bacitracin $(2.0 \mathrm{mg} / \mathrm{ml})$. $O$, Without bacitracin; $\Delta$, with bacitracin. (b) Dansylcadaverine $(20 \mu \mathrm{M})$. $\bigcirc$, Without dansylcadaverine; $\Delta$, with dansylcadaverine. (c) Methylamine (20 $\mathrm{mM})$. $O$, Without methylamine; $\Delta$, with methylamine.

3 demonstrate the complete reversal of methylamine inhibition after the removal of the inhibitor by washing, as described in Materials and Methods. Washed cells were suspended in SCM, since it has been shown (1) that suspension in fresh Tris results in a longer time lag before pair formation resumes. Even when cells were resuspended in SCM, there was a lag of ca. 45 to $50 \mathrm{~min}$ before significant numbers of cell pairs were observed. This lag was similar to that observed when untreated cells were washed and suspended in SCM and was not due to prior treatment with methylamine (or another inhibitor). In similar experiments, we have shown that dansylcadaverine and bacitracin inhibition is completely reversed after removal of the inhibitor.

Inhibition of cell pairing by chloroquine. The addition of chloroquine to mixtures of competent cells resulted in a complex pattern of inhibition strongly dependent on the concentration and the time at which the inhibitor was added.

In $10 \mu \mathrm{M}$ chloroquine (Fig. 4a), pair formation was comparable to that of the control (no inhibitor). In $25 \mu \mathrm{M}$ chloroquine (Fig. 4b), pairing occurred at a slightly lower rate and reached a lower plateau. When the concentration of chloroquine was $50 \mu \mathrm{M}$ (Fig. 4c), there was a marked decrease in the rate of pair formation and, again, the plateau reached was lower. At the latter concentration of chloroquine $(50 \mu \mathrm{M})$, the addition of the inhibitor at $t_{0}+95 \mathrm{~min}$ revealed the physiological heterogeneity between early and late cell pairs previously noted in the results obtained with dansylcadaverine and methylamine. Finally, in $100 \mu \mathrm{M}$ chloroquine (Fig. 4d), pair formation continued for only 30 to $60 \mathrm{~min}$; subsequently, cell pairs all dissociated.

\section{DISCUSSION}

We have shown that a group of chemically diverse inhibitors of receptor-mediated endocytosis inhibit cell pairing in Tetrahymena cells competent to undergo conjugation. In mammalian cell systems, these compounds have been shown to inhibit internalization of surface-bound ligands such as $\alpha$-2-macroglobulin, epidermal growth factor, and insulin (5). On the basis of

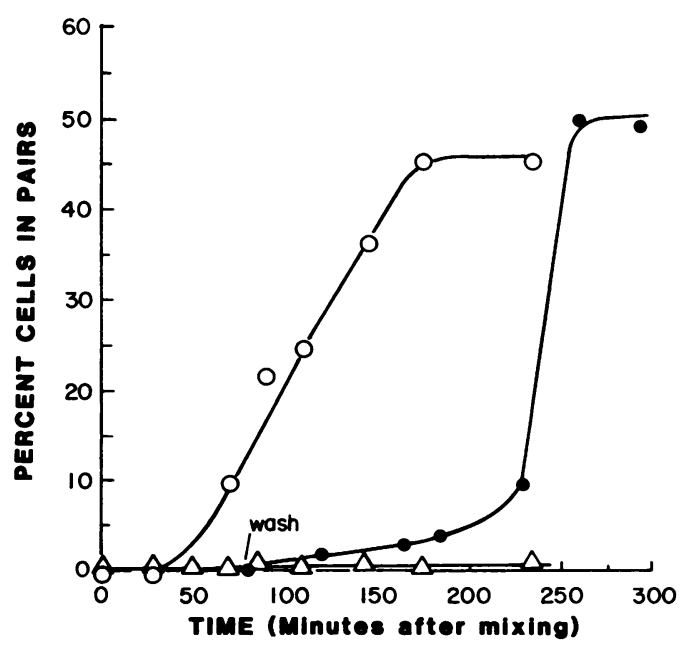

FIG. 3. Reversal of methylamine inhibition. Symbols: $O$, control (no methylamine); $\Delta$, methylamine (20 $\mathrm{mM}$ ) added at $t_{0} ; O$, inhibitor added at $t_{0}$ and removed by washing after $80 \mathrm{~min}$. 

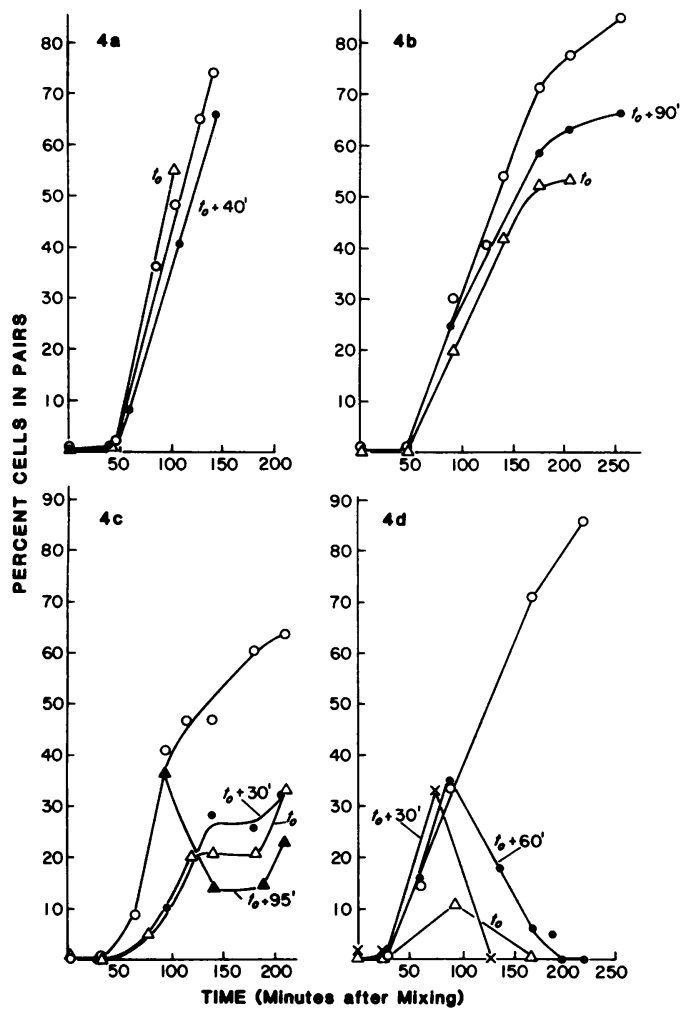

FIG. 4. Effect of chloroquine concentration on cell pair formation. (a) Chloroquine at $10 \mu \mathrm{M}$. $\bigcirc$, Control (no chloroquine). Chloroquine was added at $t_{0}(\Delta)$ and at $\mathrm{t}_{0}+40 \mathrm{~min}(\mathrm{O})$. (b) Chloroquine at $25 \mu \mathrm{M}$. $O$, Control. Chloroquine was added at $t_{0}(\Delta)$ and at $t_{0}+$ $90 \mathrm{~min}(\mathrm{O})$. (c) Chloroquine at $50 \mu \mathrm{M}$. O, Control. Chloroquine was added at $t_{0}(\Delta), t_{0}+30 \mathrm{~min}(O)$, and at $t_{0}+95 \mathrm{~min}(\Delta)$. (d) Chloroquine at $100 \mu \mathrm{M}$. $O$, Control. Chloroquine was added at $t_{0}(\Delta), t_{0}+30 \mathrm{~min}$ $(\mathrm{X})$, and at $\mathrm{t}_{0}+60 \mathrm{~min}(\mathbf{O})$.

our results and those cited (5), we speculated that there is an exchange of information during cell contact by receptor-mediated endocytosis which is inhibited by the various agents we have used. An analogy was immediately suggested to the membrane-mediated signalling observed in higher eucaryotic cells.

It is not certain that these inhibitors act by a single mechanism in all cell types. Levitzki et al. (6) have shown that the reagents used in these experiments inhibit the cytoplasmic enzyme transglutaminase in the order dansylcadaverine $>$ methylamine $>$ bacitracin. These authors have also established a direct correlation between the inhibitor constants and the effectiveness of the compound in inhibiting receptor clustering and internalization. Cell pair formation is inhibited by these compounds in the same order (i.e., dansylcadaverine $>$ methylamine $>$ bacitracin [Fig. 1a-c]).
The evidence from a variety of mammalian systems is consistent with a mechanism in which the inhibitors we used cause a depletion of the relevant surface receptors by interfering with recycling of the receptors back to the cell surface after internalization with or without bound ligand $(6,13)$. It is currently hypothesized that the cytoplasmic enzyme transglutaminase functions in the recycling pathway, although the details of such a mechanism are not known.

Chloroquine is a lysomotropic amine (i.e., a weak base that crosses the cell membrane to enter all cellular compartments and become trapped within lysosomes by protonation) which is not an inhibitor of transglutaminase. Although all amines are lysomotropic, alkalinization of the lysosome by amines has generally been ruled out as the essential step in the inhibition of endocytosis, except in the specific case of lysosomal hydrolases (12). In the latter instance, $25 \mu \mathrm{M}$ chloroquine leads to $84 \%$ inhibition of lysosomal hydrolase uptake. Since in the Tetrahymena conjugation system, concentrations of 10 and 25 $\mu \mathrm{M}$ chloroquine allow cell pair formation to continue, we concluded that alkalinization of the lysosome is not responsible for inhibition by the lysomotrope bacitracin, methylamine, or dansylcadaverine. The dissociation of cell pairs at higher concentrations of chloroquine ( 50 and 100 $\mu \mathrm{M})$ suggests that lysosomal function is required later in the cell adhesion process and in the complex morphological events which occur in cell surfaces subsequent to cell pairing and which are required for completion of conjugation.

The inhibition patterns with methylamine and dansylcadaverine (and, to some extent, chloroquine) repeatedly distinguish differences between early and late cell pairs. Such an effect has also been reported by Watanabe et al. (14) in studies on the effect of cyclohexamide on pair formation.

We concluded that the results presented above support the hypothesis that an endocytotic event(s) plays a role in cell contact-mediated recognition during the prepairing interaction in Tetrahymena. It is reasonable to presume, on the basis of results in other systems, that these amine inhibitors cause a depletion of the cell surface components required for cell recognition and pairing. The removal of these inhibitors by washing allows the replacement of the required receptors on the cell surface, and cell pair formation resumes.

\section{ACKNOWLEDGMENTS}

This research was partially supported by grant 211-7148 from the Research Foundation, State University of New York, and by Biomedical Research Support grant 211-E200-J to M.B.R. 
We thank Nancy Steinberger-Wadopian for her technical assistance.

\section{LITERATURE CITED}

1. Adair, W. S., R. Barter, R. S. Turner, and J. Wolfe. 1978. Demonstration of a cell-free factor involved in cell interactions during mating in Tetrahymena. Nature (London) 274:54-56.

2. Bruns, P., and T. B. Brussard. 1974. Pair formation in Tetrahymena pyriformis, an inducible developmental system. J. Exp. Zool. 188:337-344.

3. Bruns, P., and R. F. Palestine. 1975. Costimulation in Tetrahymena pyriformis: a developmental interaction between specifically prepared cells. Dev. Biol. 42:75-83.

4. Chatton, E., and A. Lwor. 1930. Impregnation par diffusion argentique d'eau douce, apres fixation cytologique et sans dessication. C. R. Soc. Biol. Paris 104:834-836.

5. Davies, P. J. A., D. R. Davies, A. Levitu'd, F. R. Marfied, P. Milhaud, M. C. Wilingham, and I. H. Pastan. 1980. Transglutaminase is essential in receptor-mediated endocytosis of a2-macroglobulin and polypeptide hormones. Nature (London) 283:162-167.

6. Levitzd, A., M. Willingham, and I. Pastan. 1980. Evidence for participation of transglutaminase in receptormediated endocytosis. Proc. Natl. Acad. Sci. U.S.A 77:2706-2710.

7. Maxield, F. R., M. C. Willingham, P. J. A. Davies, and I. Pastan. 1979. Amines inhibit the clustering of $\alpha 2$-macro- globulin and EGF on the fibroblast cell surface. Nature (London) 277:661-663.

8. Miyake, A. 1981. Physiology and biochemistry of conjugation in ciliates, p. 125-198. In M. Levandowsky and S. H. Hutner (ed.), Biochemistry and physiology of the protozoa, vol. 4, 2nd ed. Academic Press, Inc., New York.

9. Nebon, E. M., and L. E. Debanit. 1978. Transformation in Tetrahymena pyriformis: description of an inducible phenotype. J. Protozool. 25:113-119.

10. Oriss, E. 1981. Probable somatic DNA rearrangements in mating type determination in Tetrahymena thermophila: a review and a model. Dev. Genet. 2:185-202.

11. Oriss, E., and P. J. Brums. 1976. Induction and isolation of mutants in Tetrahymena. Methods Cell Biol. 11:248-282.

12. Sando, G. N., O. Titus-Dillon, C. W. Hall, and E. F. Neufeld. 1979. Inhibition of receptor-mediated uptake of a lysosomal enzyme into fibroblasts by chloroquine, procaine and ammonia. Exp. Cell Res. 119:359-364.

13. Van Leuven, F., J. J. Casciman, and H. Vanden Berghe. 1980. Primary amines inhibit recycling of $\alpha 2$-macroglobulin receptors in fibroblasts. Cell 20:37-43.

14. Watanabe, S., A. Toyohara, T. Seankd, and Y. Shigenalka. 1981. The relation of Concanavalin A receptor distribution to the conjugation process in Tetrahymena thermophila. J. Protozool. 28:171-175.

15. Wolfe, J., and G. W. Grimes. 1979. Tip transformation in Tetrahymena: a morphogenetic response to interactions between mating types. J. Protozool. 26:82-89. 